\title{
Erratum to: Anisotropic Diffusion Behavior of Al in Mg: Diffusion Couple Study Using Mg Single Crystal
}

\author{
SAZOL KUMAR DAS, YOUNG-MIN KIM, TAE KWON HA, RAYNALD GAUVIN, \\ and IN-HO JUNG
}

DOI: $10.1007 / \mathrm{s} 11661-013-1784-\mathrm{x}$

(C) The Minerals, Metals \& Materials Society and ASM International 2013

\section{Erratum to: METALLURGICAL AND MATERIALS TRANSACTIONS A, 2013, vol. 44, no. 6, pp. 2539-2547 \\ DOI: 10.1007/s11661-013-1636-8}

IN the calculation of the interdiffusion coefficients of two intermediate phases and the impurity diffusion coefficients of $\mathrm{Al}$ in hcp $\mathrm{Mg}$, a small numerical error was found. The error does not change the main conclusions of the work but can lead to small errors in the diffusion calculations. The following is a revision of the interdiffusion coefficients and impurity diffusion coefficient. The numbering of figures, tables and references used in this erratum are the same as the original paper for convenience.

Interdiffusion coefficients for two intermediate phases $\left(\mathrm{Mg}_{17} \mathrm{Al}_{12}\right.$ and $\left.\mathrm{Mg}_{2} \mathrm{Al}_{3}\right)$ were calculated using the Heuman-Matano method ${ }^{[13]}$ by identifying the Matano plane from Al concentration profile throughout the whole diffusion zone quantified by Electron Probe Micro Analyzer (EPMA). For example, the position of the Matano plane for the sample annealed after 72 hours at $693 \mathrm{~K}\left(420{ }^{\circ} \mathrm{C}\right)$ is marked in Figure 1. The revised interdiffusion coefficients for the $\mathrm{Mg}_{17} \mathrm{Al}_{12}$ and $\mathrm{Mg}_{2} \mathrm{Al}_{3}$ intermediate phases are presented in Table III and in Figure 4 with comparison to previous studies. ${ }^{[5,8]}$ Our results are in good agreement with Brennan et al. ${ }^{[8]}$

The revised values for the Al impurity diffusion coefficient in hcp $\mathrm{Mg}$ from the multiphase diffusion calculation used in the original paper are plotted in Figure 7(a). In order to confirm the impurity diffusion, a Gaussian solution of Fick's second law ${ }^{[29]}$ is also applied to analytically calculate impurity diffusion coefficient in this erratum. In the analytical method, the impurity diffusion coefficient for each sample was calculated from the slope of $\ln (\mathrm{Al}$ concentration) vs square of penetration distance in dilute $\mathrm{Al}$ concentration region of hcp $\mathrm{Mg}$ solid solution. As can be seen in Figure 7(a), the analytical results are in good agreement with the results obtained from multiphase diffusion simulation. The revised Al impurity diffusion coefficients, depending on the orientation of hep $\mathrm{Mg}$, were plotted in Figure 7(b) and compared with previous studies. ${ }^{[4,7,9]}$ The revised optimized mobilities of $\mathrm{Al}$ in hcp $\mathrm{Mg}$ along the $a$ - and $c$-axis of $\mathrm{Mg}$ crystal are

$$
\begin{aligned}
& \Omega_{\perp A l(\mathrm{hcp} \mathrm{Mg})}=3.23 \times 10^{-7} \exp (-148955 / R T) \\
& \Omega_{|| A l(\mathrm{hcp} \mathrm{Mg})}=6.32 \times 10^{-7} \exp (-153947 / R T)
\end{aligned}
$$

The impurity diffusion coefficient values for $\mathrm{Al}$ in hcp $\mathrm{Mg}$ from the present experimental study are

$$
\begin{aligned}
D_{\perp A l} & =4.86 \times 10^{-3} \exp (-154484 / R T) \\
D_{|| A l} & =9.51 \times 10^{-3} \exp (-159476 / R T)
\end{aligned}
$$

SAZOL KUMAR DAS, Ph.D. Student, RAYNALD GAUVIN, Professor, IN-HO JUNG, Assistant Professor, are with the Department of Mining and Materials Engineering, McGill University, 3610 University Street, Montreal, QC H3A 0C5, Canada. Contact e-mail: in-ho.jung@mail.mcgill.ca YOUNG-MIN KIM, formerly Post Doctoral Fellow with Department of Mining and Materials Engineering, McGill University, is now Senior Researcher with Korea Institute of Industrial Technology (KITECH), Incheon 406-840, Republic of Korea. TAE KWON HA, Associate Professor, Department of Advanced Metal and Materials Engineering, Gangneung-Wonju National University, Gangneung 210-702, Republic of Korea.

The online version of the original article can be found under doi: 10.1007/s11661-013-1636-8.

Article published online May 16, 2013 


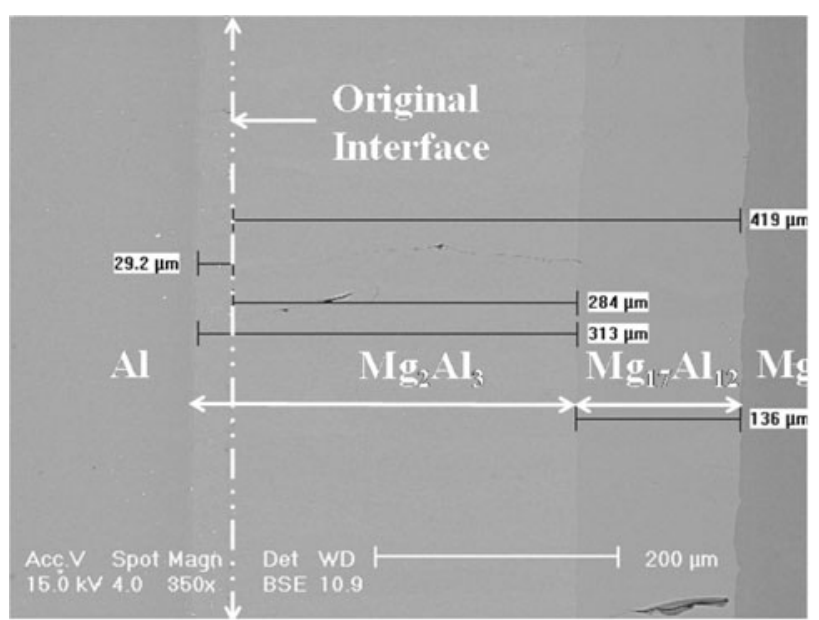

(a)

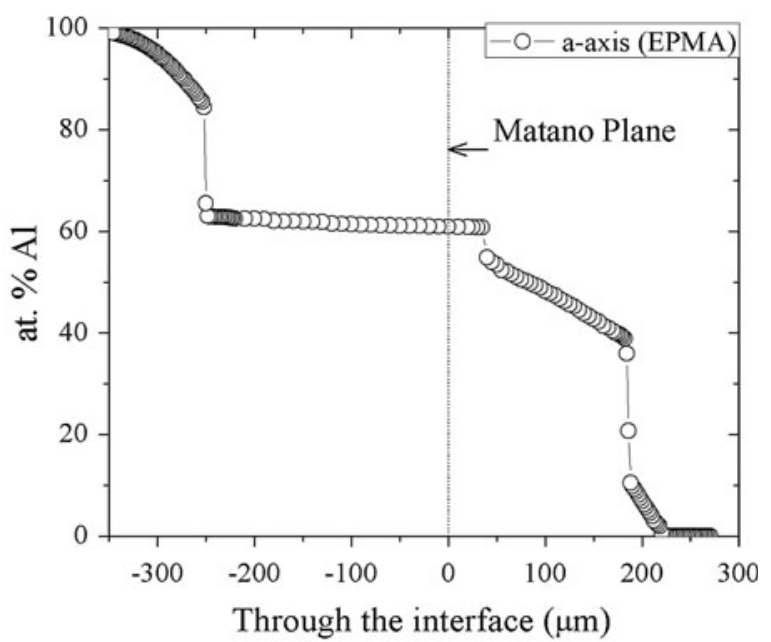

(b)

Fig. 1-Diffusion couple experiment with single crystal Mg: (a) Interface microstructure of diffusion couple (SEM BSE image) after $72 \mathrm{~h}$ annealing at $693 \mathrm{~K}\left(420^{\circ} \mathrm{C}\right),(b) \mathrm{Al}$ concentration profile (WDS line scan) through the interface with the Matano plane.

Table III. Interdiffusion Coefficients for $\mathrm{Mg}_{17} \mathrm{Al}_{12}$ and $\mathrm{Mg}_{2} \mathrm{Al}_{3}$ Phases from the Present Study in Comparison to the Previous Studies ${ }^{[5,8]}$

\begin{tabular}{|c|c|c|c|c|c|}
\hline \multirow[b]{2}{*}{ Orientation } & \multicolumn{2}{|c|}{$\mathrm{Mg}_{17} \mathrm{Al}_{12}$} & \multicolumn{2}{|c|}{$\mathrm{Mg}_{2} \mathrm{Al}_{3}$} & \multirow[b]{2}{*}{ Reference } \\
\hline & $D_{\mathrm{o}}\left(\mathrm{m}^{2} / \mathrm{s}\right)$ & $Q(\mathrm{~kJ})$ & $D_{\mathrm{o}}\left(\mathrm{m}^{2} / \mathrm{s}\right)$ & $Q(\mathrm{~kJ})$ & \\
\hline $\begin{array}{l}a \text {-axis } \\
c \text {-axis }\end{array}$ & $\begin{array}{l}3.59( \pm 0.82) \times 10^{-5} \\
2.89(+0.59) \times 10^{-5}\end{array}$ & $109.9396( \pm 2.18)$ & $2.96( \pm 1.69) \times 10^{-6}$ & $78.9177( \pm 8.43)$ & present Study \\
\hline $\begin{array}{l}c \text {-axis } \\
\text { Polycrystalline }\end{array}$ & $1.89( \pm 0.39) \times 10$ & $\begin{array}{l}109.2949( \pm 3.13) \\
129.7\end{array}$ & $\begin{array}{l}1.53( \pm 0.31) \times 10 \\
9.6 \times 10^{-6}\end{array}$ & $\begin{array}{l}16.2443( \pm 2.3 /) \\
84.8\end{array}$ & Brenann et al ${ }^{[8]}$ \\
\hline Polycrystalline & $9.9(+11.9 ;-5.4) \times 10^{-5}$ & $117.57( \pm 4.18)$ & $2.4(+3.3 ;-1.4) \times 10^{-8}$ & $56.90( \pm 4.60)$ & $\begin{array}{l}\text { Funamizu and } \\
\text { Watanabe }^{[5]}\end{array}$ \\
\hline
\end{tabular}




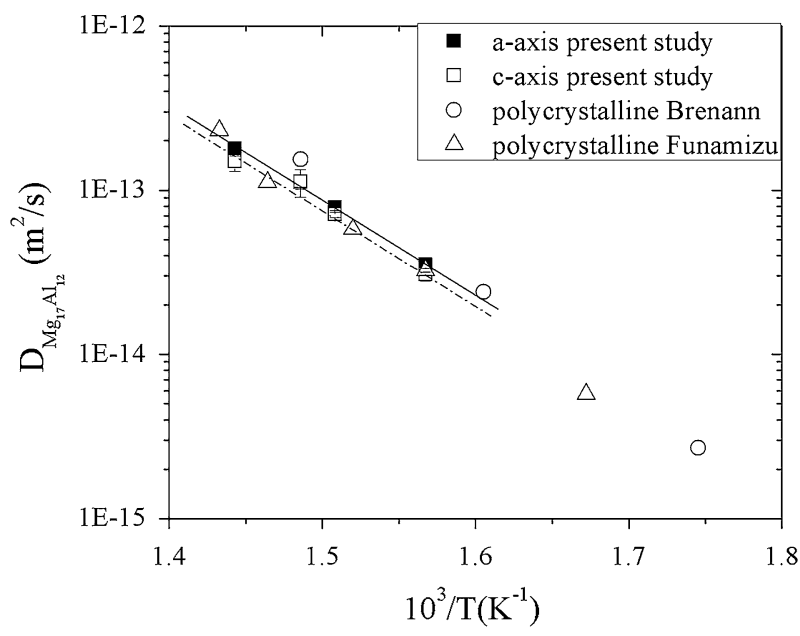

(a)

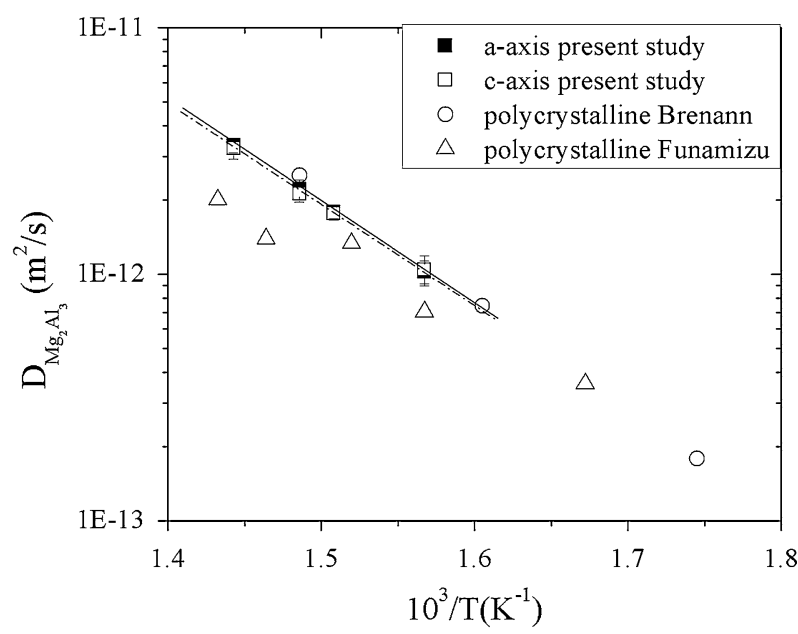

(b)

Fig. 4-Variation of the inter-diffusion coefficients of intermediate phases: (a) $\mathrm{Mg}_{17} \mathrm{Al}_{12}$ phase, (b) $\mathrm{Mg}_{2} \mathrm{Al}_{3}$ phase with temperature in comparison to the previous studies. ${ }^{[5,8]}$

The present activation energies of the diffusion of $\mathrm{Al}$ in hcp $\mathrm{Mg}$ along the $a$ - and $c$-axis are $154.48 \pm 3.86 \mathrm{~kJ} /$ $\mathrm{mol}$ and $159.48 \pm 2.45 \mathrm{~kJ} / \mathrm{mol}$, respectively.

\section{REFERENCES}

4. G. Moreau, J.A. Cornet, and D. Calais: J. Nucl. Mater., 1971, vol. 38, pp. 197-202.

5. Y. Funamizu and K. Watanabe: Trans. Jpn. Inst. Met., 1972, vol. 13, pp. 278-83.

7. S. Brennan, P.P. Andrew, R.K. Coffey, Y. Shon, N. Kulkarni, and P. Todd: $M g$ Tech. TMS, 2010, pp. 537-38.

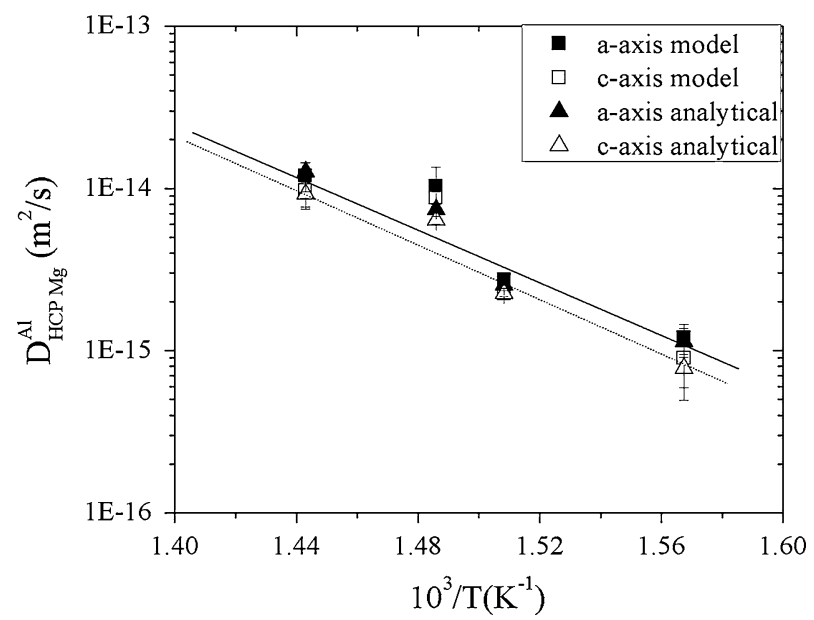

(a)

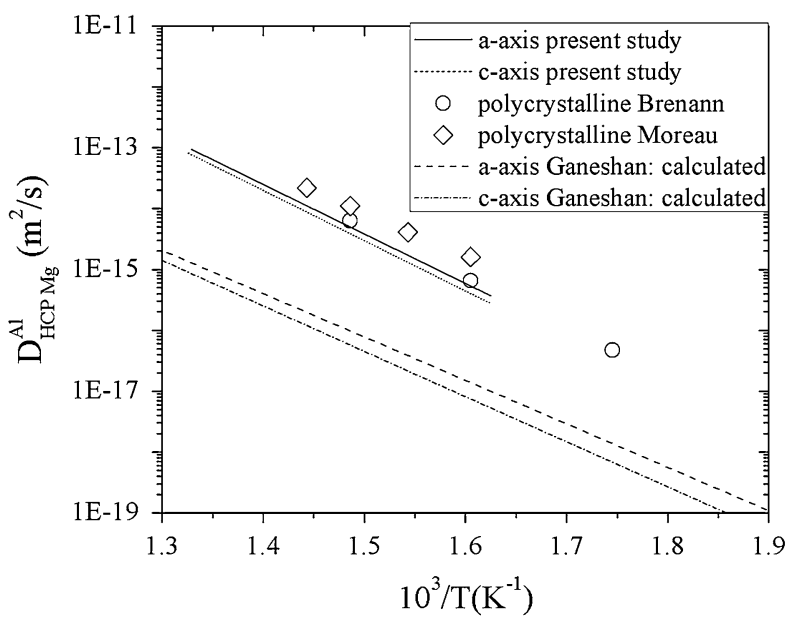

(b)

Fig. 7-Variation of $\mathrm{Al}$ impurity diffusion coefficients in hcp $\mathrm{Mg}$ along its $a$ - and $c$-axis directions with temperature. (a) Present results from single crystal diffusion experiment (model and analytical represent the calculations by multiphase diffusion simulation and analytical method, respectively), and (b) comparison with the previous data derived from polycrystalline samples ${ }^{4,7]}$ and the first principles calculations. ${ }^{[9]}$

8. S. Brennan, K. Bermudez, N. Kulkarni, and Y. Shon: Mg Tech. TMS, 2011, pp. 549-52.

9. S. Ganeshan, L.G. Hector Jr., and Z.K. Liu: Acta Mater., 2011, vol. 59, pp. 3214-28.

13.T. Heumann: Z. Phys. Chem., 1952, vol. 201, pp. 168-89.

29.W. Jost: Diffusion in Solids, Liquids and Gases, 3rd ed., Academic Press, New York, 1960, p. 16 